\title{
A COMPARISON OF THE SEISMIC DESIGN REQUIREMENTS IN THE NEW ZEALAND LOADINGS STANDARD WITH OTHER MAJOR DESIGN CODES
}

\author{
Richard Fenwick ${ }^{1}$, David Lau ${ }^{2}$ and Barry Davidson ${ }^{3}$
}

\begin{abstract}
SUMMARY
A series of ductile moment resisting reinforced concrete frames are sized to meet the minimum seismic provisions of the New Zealand Loadings Standard, NZS 4203-1992, the Draft NZ/Australian Loadings Standard, the Uniform Building Code, UBC-1997, the International Building code, IBC 2000 (1998 draft) and Eurocode 8 (1998 draft). The results of the analyses allow valid comparisons to be made between the different codes. It is shown that comparisons of individual clauses can be misleading due to the many interactions that occur between clauses.

Comparative analyses were made for the buildings described above located in both high and low seismic regions. It is shown that the strength and stiffness requirements for both the New Zealand Loadings Standard and the Draft Standard are low compared with the other codes of practice in the high seismic zone. It is recommended that the required design strengths in the Draft NZ/Australian Standard be increased.
\end{abstract}

\subsection{INTRODUCTION}

Any direct comparison of apparently similar clauses and formulae in different codes of practice can be misleading due to the interrelationship with other clauses. For example in comparing the allowable inter-storey drift limits given in different codes allowance has to be made for;

- the design lateral forces;

- the rules used for assessing the stiffness of the members;

- the increase in displacements required to allow for PDelta actions.

In the five codes of practice that are considered in this paper, the design seismic lateral forces on a frame building with the same structural dimensions varies by a factor of close to three. The stiffness (EI) of a beam evaluated following the recommendations of the New Zealand Structural Concrete Standard (NZS3101) is approximately 30 percent of the value determined following the recommendations of Eurocode 8. Furthermore the way in which the limiting inter-storey deflections are defined is different in the codes, as are the requirements for adjusting deflections to allow for P-delta actions. This makes comparisons of individual clauses meaningless. However, looking at the results of comparative analyses made using different codes does provide a valid basis of comparison.

In this paper comparisons are made between the seismic strength and stiffness requirements of five codes, namely the
New Zealand Loadings Standard [1], the draft NZ/Australian Loadings Standard [2], the Uniform Building Code [3], the International Building Code, UBC 2000 (1998 draft)[4] and Eurocode 8 (draft 1998) [5]. The results of comparative analyses that have been made for a series of multi-storey ductile concrete frame buildings are reported in terms of the required strengths and stiffness values. No attempt is made to compare the detailing or the strength enhancement that may be specified to achieve ductile behaviour. Readers interested in these aspects are referred to reference [6].

It should be noted that the Draft NZ / Australian Loadings Standard has been included to enable this document, which is still being developed, to be compared with existing codes of practice. The draft code, as in the $20^{\text {th }}$. February 2002 version has been used in this study. It should be noted that a number of changes have subsequently been made and further changes are planned before the publication of this Standard.

\subsection{DESCRIPTION OF BUILDINGS}

A series of multi-storey buildings, consisting of 6,12,18 and 24 storey structures, were sized to comply with the minimum requirements of the codes. All the buildings were assumed to have the same floor plan, as shown in Figure 1. For simplicity stairwells and lift shafts etc. were not considered. It was assumed that the buildings would be for general office use. As such they attract an importance factor of 1.0 in all the codes except the draft NZ/Australian code, where the

\footnotetext{
${ }_{1}^{1}$ Dept. of Civil \& Environmental Engineering, University of Auckland (Life Member).

${ }^{2}$ Graduate Student, Dept. of Civil \& Environmental Engineering, University of Auckland (Member).

${ }^{3}$ Dept. of Civil \& Environmental Engineering, University of Auckland (Member).
} 
factor is 1 for the 6 and 12 storey buildings and 1.3 for the 18 and 24 storey buildings. In each building two ductile perimeter concrete moment resisting frames provide the lateral force resistance in the $\mathrm{x}$ direction, as shown in Fig. 1. Structural walls on the other two sides provide the lateral resistance in the y direction and resist any torsional actions. Consequently any difference arising from the treatment of accidental torsion in the different codes is not included in the analyses. It was assumed that laterally flexible internal framing resists the majority of the gravity load, and that the floors act as rigid diaphragms. With this assumption, for earthquake actions in the $\mathrm{x}$ direction, half the seismic weight at each level acts with each perimeter frame. This weight, which has been taken as $1,700 \mathrm{kN}$, corresponds to approximately $7 \mathrm{kN} / \mathrm{m}^{2}$ of dead and seismic live load. The small differences in live load specified in the three codes have been ignored, as have the differences in dead load, which occurs with the different designs due to changes in section size. The inter-storey height was taken as $3,400 \mathrm{~mm}$ in all cases.

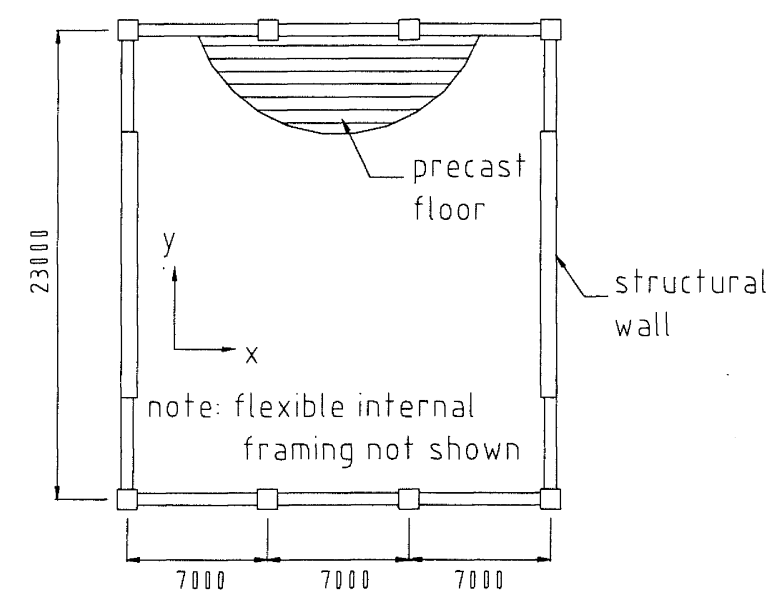

Figure 1: Floor plan for buildings

\subsection{SUB SOIL CONDITIONS AND SEISMICITY}

The site subsoil conditions were chosen to match the midrange of the intermediate soils, category (b), in the New Zealand Loadings Standard [1]. This was assessed as having a site period of 0.45 seconds. With the Draft NZ/Australian Standard [2] this corresponds to site subsoil class C. In the Uniform Building Code [3] there are six subsoil categories, which range from hard rock, $s_{\mathrm{a}}$, to very soft deposits, $\mathrm{s}_{\mathrm{f}}$. The same categories are adopted in the International Building Code [4]. The mid range of the sub-soil category $s_{d}$, was assessed as having the site period of 0.45 seconds. Eurocode 8 [5] contains three subsoil categories. In this case the site period of 0.45 seconds was assessed as lying mid-way between categories A and B. Hence the design spectrum was taken as the average of those specified for the two sub-soil categories.

Two different seismicity levels were considered. The first was made for a site located in the highest seismic zone recognised in the New Zealand Standard, NZS4203-1992, which has a zone factor of 1.2. The second site is in lowest seismic zone recognised in this Standard, which has a zone factor of 0.6 . The analyses were repeated for each seismicity level. With the draft NZ/Australian Standard the high seismic zones in the New Zealand Loadings Standard has been replaced with a more detailed zoned areas. Consequently no direct comparison is possible based on a specific location is possible.

\subsection{Elastic design spectra}

The basic seismic hazard spectra in the New Zealand Standard, NZS4203-1992 and in the draft NZ/Australian Standard, are based on a return period of 450 years, while the corresponding values in the UBC-97 and EC8 codes are based 475 years. With the IBC 2000 code the basic return period is 2500 years, but the spectral values are multiplied by $2 / 3$ for the purposes of design. For the high to moderate seismic zones this corresponds approximately to a return period of 500 years.

By selecting appropriate seismic zones and soil conditions with each of the five codes of practice the basic elastic response spectra could be made similar to each other in both the shape and the magnitudes of spectral values. The resultant spectra are shown on Fig. 2 . It can be seen that there is very little difference in the numerical values for the period range of 1 to 3 seconds. The use of these spectra, which as noted above are very similar to each other, enables differences that arise in the way the spectral values are used to derive the design values to be high lighted. Details of how the spectral values were found with each code are given in the following sub-sections.

\subsection{High Seismic Zone}

For the New Zealand Standard [1] a zone factor of 1.2 was used. In the draft NZ/Australian code seismicity in broken down into smaller zones. A hazard factor ( $\mathrm{Z}$ value) of 0.48 was used as this gave a close match to the hazard spectrum with a zone factor of 1.2 in the New Zealand Standard [1]. To match the resultant spectra with the UBC-1997 code the zone factor was interpolated between 0.3 and 0.4 and it was taken as 0.36 . The corresponding $\mathrm{C}_{\mathrm{a}}$ and $\mathrm{C}_{\mathrm{v}}$ parameters were 0.408 and 0.6 respectively. For the IBC code an identical spectrum is obtained to the UBC code by taking "site coefficients and adjusted maximum earthquake spectral response parameters", $\mathrm{S}_{\mathrm{S}}$ for the short period and $\mathrm{S}_{1}$ for the 1 second value, as 1.53 and 0.60 respectively. These values are defined in clause 1615.1.2 of the IBC code. With the EC8 code [5] a peak ground acceleration of 0.48 was used. With these values there was little difference between the spectral curves for the codes in the period range of 1 to 3 seconds. For periods greater than this limit the Eurocode and draft NZ/Australian values are smaller than the others. This arises as these spectral values in this range are based on the assumption that a maximum displacement is reached. There is relatively close agreement in the spectral values between 0.6 and 1 second. The resultant spectra are shown in Fig. 2 in the upper set of curves.

\subsection{Low Seismic Zone}

For the low seismic zone a zone factor of 0.6 was used with the current New Zealand Loadings Standard. To obtain equivalent values with the draft NZ/Australian Standard a hazard factor (equivalent to a zone factor) of 0.24 was used. With the UBC code interpolation between the seismic zones gave a zone factor of 0.14 , with corresponding the $C_{a}$ and $C_{v}$ parameters equal to 0.207 and 0.3 respectively. With the 
IBC code an identical spectrum to the UBC spectrum was obtained by using coefficients for $S_{\mathrm{s}}$ and $\mathrm{S}_{1}$ of 0.582 and 0.233 respectively. With the $\mathrm{EC} 8$ code the peak ground acceleration, $a_{\mathrm{g}}$, has been taken as 0.24 . As with the high seismic zone with these parameters the spectral values are in good agreement with each other in the period range of 1 to 3 seconds, and there is close agreement in the from 0.6 to 1 second period range. The different spectra are shown in Figure 2 in the lower set of curves.

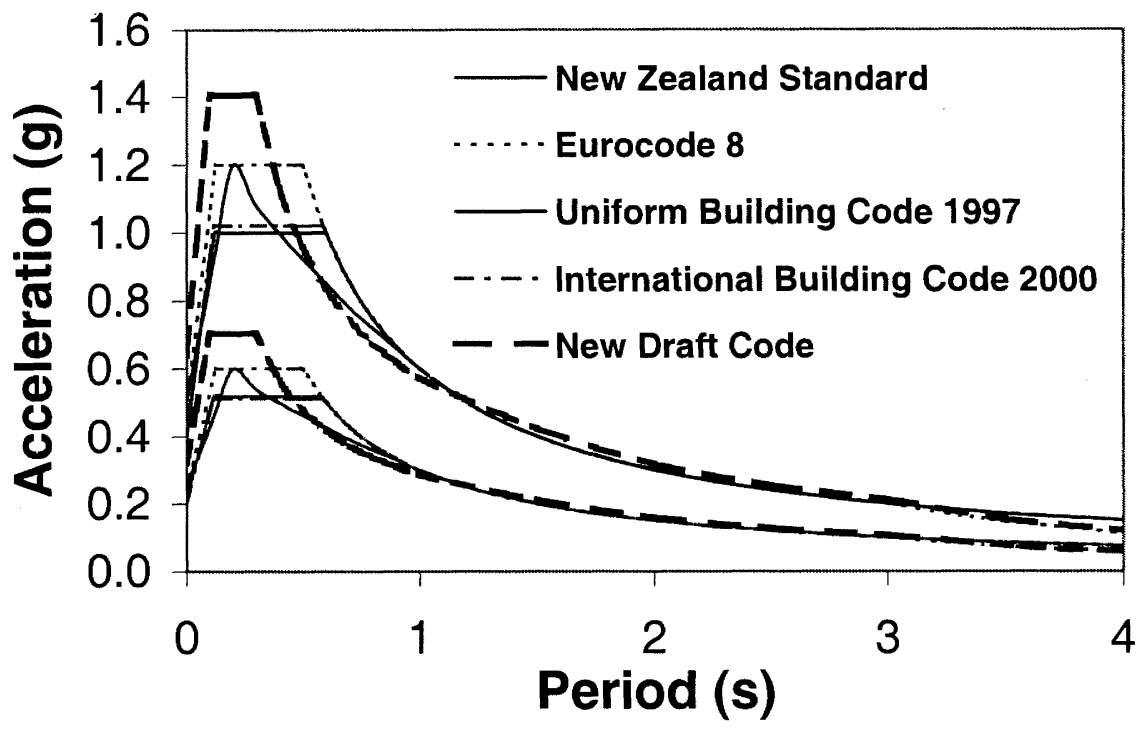

Figure 2: Response spectra for "nominal 500 year return period" for high and low seismic zones.

\subsection{ANALYSES}

\subsection{General}

A "basic set of frames" was proportioned for the $6,12,18$ and 24 storey buildings. Practical member sizes were chosen so that the critical design inter-storey deflections were close, but not exactly equal to, the limits given in the New Zealand Standard over the height of the building for the high seismic zone. To achieve this, the member sizes were changed in six storey blocks. The section properties used in the analyses were assessed following the recommendations in the New Zealand Concrete Structures Standard [8].

The frames were analysed using the modal method with the contributions from the different modes being combined by the square root of the sum of the squares. The analyses were made using the structural analysis package, SAP 2000 [9]. As the modes were well separated there was no need to use the CQC or other equivalent combination approaches.

For the high seismic zone the "basic set of frames" were analysed to see if they would meet the requirements of each of the codes in turn. In each case the section properties and design actions were assessed from the member sizes following the recommendations of the code, or associated code, being considered. Analyses were made for each frame, and these were repeated with all the second moments of area being multiplied by a constant, which was adjusted in successive analyses until the critical inter-story deflection just reached the limiting value permitted by the particular code. The results of these analyses were then compared. For the New Zealand Standard only small adjustments were required as the deformation of the basic set of frames was close to the code limit.
For the low seismic zone a different approach had to be followed, as the method used for the high seismic zone gave unrealistically flexible building. For this case the structural actions were found for the "basic set of frames" and these were only modified where their stiffness proved to be insufficient to meet the minimum requirements of the code being considered.

For the New Zealand Loadings and Structural Concrete Standards $[1,8]$ the maximum value of the structural ductility factor, $\mu$, is taken as 6 . The same limit also applies to the draft NZ/Australian Loadings Standard [2]. With the higher frames the minimum base shear requirement in both seismic zones meant that this level of ductility was not required and consequently a lower value was used. With the UBC code [3] the reduction factor, $R$, was 8.5 (special moment resisting frames). For the IBC 2000 code [4] the response modification factor was 8 (special reinforced concrete moment frames), and for the EC 8 code [5] the maximum value of the behaviour factor, q, (high ductility class) was taken as 5. As with the New Zealand Standard, minimum base shear strengths meant that in some of the structures this level of behaviour factor was not required and a lower value was used. Recent indications are that the high ductility class in EC8 will not be adopted in the next draft. This is likely to result in an appreciable increase in the required strength of frame structures designed to the requirements of this code.

\subsection{Section Properties}

As previously noted each code contains its own recommendations for determining the appropriate section properties. For the analyses to the New Zealand Standard and the draft NZ/Australian Standard the recommendations contained in the Commentary to the Concrete Standard, NZS3101-1995 [8], were followed. The designer is required to allow for the loss of stiffness arising from flexural 
cracking. It is recommended that moment of inertia of flanged beams should be taken as 0.35 times the value based on the gross section $\left(\mathrm{I}_{\mathrm{g}}\right)$ while for rectangular beams a value of 0.4 is suggested. For columns it is suggested that the effective moment of inertia is taken as $0.4 \mathrm{I}_{\mathrm{g}}$ where there is no axial load and $0.8 \mathrm{I}_{\mathrm{g}}$ where the axial load ratio, $\mathrm{N}^{*} / \mathrm{A}_{\mathrm{g}} \mathrm{f}_{\mathrm{c}}{ }^{\prime}$, is equal to or greater than 0.5 . The corresponding factor in the UBC and IBC codes was 0.5 , and it is applied to both columns and beams. With Eurocode 8 no allowance for flexural cracking is required though there is a warning that this may need to be considered in some cases.

In all cases it was assumed the design cylinder strength of the concrete was $30 \mathrm{MPa}$. With this value the modulus of elasticity was almost identical for the New Zealand Structural Concrete Standard [8], the UBC [3] and IBC [4] codes. However, the value given in the Euro Structural Concrete code (EC2 [10]) for the elastic modulus of concrete, is appreciably greater than the corresponding value in the New Zealand Standard [8]. The consequence of the differences in $\mathrm{E}$ and $\mathrm{I}$ is that for the identical beam, the Eurocode 8 stiffness value is in excess of three times the corresponding value found from the New Zealand recommendations. This particular variation has direct implications on how the different inter-storey drift limits given in the codes should be interpreted.

\subsection{Limiting Inter-storey Deflections}

In all cases limiting inter-storey deflections given in the codes are specified for the ultimate limit case, though the form of this limit varies. In the New Zealand Standard and the draft NZ/Australian Loadings Standard the limiting ratio of inter-storey deflection to storey height, for buildings of $30 \mathrm{~m}$ or more in height, is $\mathbf{0 . 0 1 5}$, and as such this applies to the 12,18 and 24 storey structures considered in this paper. For lower buildings some increase in inter-storey deflection is permitted, with the limiting ratio being 0.020 for a $15 \mathrm{~m}$ high building. For buildings with a height between these two limits the maximum permissible inter-storey drift is found by linear interpolation. For the 6 storey building the critical ratio is 0.0182 . There is a significant difference between these two codes in the way the limits are applied. In the New Zealand Standard the deflection limit applies in all situations, and this includes the case where the minimum base shear controls the strength. However, in the draft NZ/Australian Standard this is not the case. With this code, the minimum storey shears are defined in the non-seismic part of the document. However, the inter-storey deflection limit applies only to the forces found in the seismic analysis and not to the case where the storey shears are limited by the minimum requirements, which are contained in Part 0 of the draft standard. (The authors understand that it is intended to change this situation in the Standard).

The inter-story drift limits in the UBC and IBC codes are both 0.020 times the inter-storey height for the buildings considered in the paper. With the IBC code the permissible inter-storey deflection to storey height ratio is reduced for building with an importance factor of more than 1 . In both the UBC and IBC codes some increase in inter-storey deflection is permitted for building with fundamental periods of less than 0.7 seconds, or where it can be demonstrated that greater drifts can be tolerated by the structure and associated non-structural components.
With the EC8 code the maximum permissible inter-storey deflection for the ultimate limit state is defined such that the stability coefficient, $\theta$, which is found in connection with $P$ delta actions, is not allowed to exceed 0.3. In practice this value is seldom critical. A second limit is also given in the code that applies to the serviceability limit-state. This value limits the ratio of the inter-story deflection divided by the storey height to 0.006 for the type and usage of buildings considered in this paper. The serviceability limit-state in this case involves some inelastic deformation.

\subsection{BASE SHEAR, DESIGN ACTIONS AND DEFLECTIONS}

\subsection{General}

Each of the codes contain its own set of rules for establishing the response spectrum to be used in the modal analysis and for scaling the results from this analysis to allow for inelastic behaviour both in terms of strength and deformations. Important features related to frame structures considered in this paper are described in the following sub-sections. Additional details should be obtained from the individual codes [1, 2, 3, 4 and 5] and reference 7 .

\subsection{New Zealand Loadings Standard [1]}

The design elastic response spectrum, described in section 3.1 , is multiplied by the structural performance factor, which is taken as 0.67 . Using the modal response spectrum method a set of elastic response actions is obtained. Included in these is the base shear, $V_{\text {base(1). The "elastic response }}$ actions" are reduced by multiplying by a factor, $\mathrm{S}_{\mathrm{m}}$, (which is less than 1.0) to allow for reduction in strength associated with ductile behaviour. This gives a set of initial strengths, which subsequently have to be increased for P-delta actions to give the design strengths. The terms "elastic response actions" and "initial strengths" are not used in the code, but are used here to clarify the process. The value of $S_{m}$ is taken as the largest of $S_{\mathrm{m} 1}, S_{\mathrm{m} 2}$ or $S_{3}$, as given by the following criteria.

- $\mathrm{S}_{\mathrm{m} 1}$ is tabulated in the code. For structures with a fundamental period equal or greater than 0.7 seconds its value is equal to $1 / \mu$, where $\mu$ is the structural ductility factor. The maximum value of 6 applies to ductile concrete frame structures.

- A factor $S_{m 2}$, such that the product of $S_{m 2}$ and the elastic response base shear $\left(\mathrm{V}_{\text {base1 }}\right)$, is equal to $\mathrm{K}_{\mathrm{m}}$ times the equivalent static base shear. For buildings that meet the regularity requirements of the standard the value of $\mathrm{K}_{\mathrm{m}}$ is 0.8 . For all other cases its value is 1.0 . For all the structures considered in this paper the value is 0.8 . This limit means that the base shear is never less than $80 \%$ of the equivalent static value.

- A factor, $S_{3}$, such that the product of $S_{3}$ and the elastic response base shear $\left(\mathrm{V}_{\text {base(1) }}\right)$ is not less than $0.03 \times \mathrm{K}_{\mathrm{m}}$ times the seismic weight $\left(\mathrm{W}_{\mathrm{t}}\right)$. Where this criterion controls, the maximum permitted structural ductility is not required by the code rules, and a reduced value can be determined by equating the first and third criteria for the expressions for $S_{\mathrm{m} 1}$ and $S_{3}$. This gives the equation -

$$
\mathrm{V}_{\text {base(1) }} / \mu=0.03 \mathrm{~K}_{\mathrm{m}} \mathrm{W}_{\mathrm{t}} \text {. }
$$


This equation places a minimum limit on the base shear of $0.024 \mathrm{~W}_{\mathrm{t}}$.

To obtain the design strengths the values of $S_{m}$ times the elastic response values have to be increased to allow for Pdelta actions as described in section 7 .

The displacements associated with the "initial strengths" are taken as equal to the "elastic response values". This corresponds to the equal displacement principle in which elastic responding structures are assumed to sustain the same peak displacement as ductile structures. For the buildings considered in this paper the critical inter-storey drifts were taken from the elastic response values, and these were increased to allow for P-delta actions as described in section 7.

\subsection{Draft NZ/Australian Loadings Standard [2]}

With this code the design spectrum is taken as the basic hazard spectrum, multiplied by the hazard factor, $Z$, the $S_{p}$ factor and the return period factor, $R$. The resultant value is then divided by the structural ductility factor, $\mu$, to allow for inelastic deformation. For these analyses the $\mathrm{Z}$ values are 0.48 and 0.24 for the high and low seismic zones respectively, the $S_{p}$ factor has a value of $2 / 3$, and the return period factor, $R$, has value a of a value of 0.2 for the serviceability limit state, and for the ultimate limit state it has a value of 1.0 for the 6 and 12 storey buildings and 1.3 for the 18 and 24 storey buildings. No minimum values are specified in the seismic provisions. However, the general provisions in Part 0 of the draft require all structures to be able to sustain a story shear of 0.025 times the dead load and long-term live load supported by the storey being considered. This is part of the robustness provisions.

The design displacements are calculated in two ways. The critical values for these structures are found by multiplying the values found from the design response spectrum by the structural ductility factor, $\mu$. The resultant values have to be increased to allow for P-delta effects as described in section 7.

\subsection{Uniform Building Code [3]}

The elastic response spectrum described in section 3.1 is used with a modal analysis to give the "elastic response parameters" (moments, shears and forces and deflections). These values are reduced to allow for ductile behaviour to give the "design actions", by multiplying by the largest of the factors given by the following criteria.

- A factor of $1 / \mathrm{R}$, where $\mathrm{R}$ is the strength reduction factor, which has a value of 8.5 for the special moment resisting frames considered in this paper.

- A factor such that the product of this value and the elastic response parameter base shear is equal to 90 percent of the equivalent static base shear. In assessing the equivalent static base shear the fundamental period of the building that is used is not allowed to exceed the larger of $-$

(a) the theoretical value found in the modal analysis, $T_{1}$ or

(b) a value, $T_{a}$, given by the equation below

$\mathrm{T}_{\mathrm{a}}=0.073 \mathrm{~K} \mathrm{~h}_{\mathrm{n}}^{3 / 4}$ where $\mathrm{K}$ is 1.3 for the high and 1.4 for the low seismic zones respectively, and $h_{n}$ is the height of the building in metres. The coefficient, 0.073 , applies to buildings where the lateral resistance is provided by reinforced concrete moment resisting frames and eccentrically braced structural steel buildings. Where structural steel moment resisting frames are used the 0.073 coefficient is replaced by a value 0.085 , while the corresponding value with wall buildings is 0.049 .

In all the frames considered in this paper the limit given by $\mathrm{T}_{\mathrm{a}}$ was critical. The scaling of actions associated with the factored $\mathrm{T}_{\mathrm{a}}$ value applies to the design forces, which are the bending moments, shears and axial forces. It does not apply to the lateral displacements, which are based on the original elastic response parameters. The increase in design forces, when the $T_{a}$ value is critical, only occurs where a structure is relatively flexible. It is these buildings that are sensitive to P-delta actions. Though not stated in the code this is an effective means of helping to control P-delta actions, and it is the main reason why the UBC P-delta provisions on their own are inappropriate for use with the New Zealand Loadings Standard.

- The design action base shear is not allowed to be less than either 90 percent of the equivalent static base shear or a value of $0.11 \mathrm{C}_{\mathrm{a}} \mathrm{W}_{\mathrm{t}}$, where $\mathrm{C}_{\mathrm{a}}$ is the peak ground acceleration. When this limit is critical the base shear and design forces, but not the lateral displacements, are scaled. In addition there is a further minimum base shear value specified for the highest seismic zone (Eq. 30.7 in reference 2), which is associated with near fault effects that have to be considered for both forces and displacements.

To allow for inelastic deformation associated with ductile behaviour the "elastic response deflections" are all multiplied by $0.7 \mathrm{R}$. The 0.7 value corresponds to the structural performance factor $(0.67)$ of New Zealand practice. With this value the corresponding structural ductility factor for ductile frame structures, in New Zealand terms, is equivalent to 5.95. When the load combinations are found two further factors have to be applied as indicated below.

1. For concrete and masonry structures all values are increased by a factor of 1.1 (clause 1612.2.1 exception 2).

2. For structures with a low level of redundancy, design strengths have to be multiplied by a reliability/redundancy factor, $\rho$ (clause 1630.1.1 in reference 3 ), which was unity for all the frames considered in this paper.

\subsection{International Building Code [4]}

The procedure followed in this code has many similarities to the UBC code. With the IBC code a modal analysis is carried out using the elastic response spectrum divided by $R / I$, where $R$ is the strength reduction factor and $I$ is the importance factor. For these structures $\mathrm{R}$ has a value of 8 and I has a value of 1.0 . With this response spectrum the base shear, $V_{t}$, is found. In all cases an equivalent static base shear, $\mathrm{V}$, is also calculated, and where the modal base shear, $\mathrm{V}_{\mathrm{t}}$, is found to be less than $\mathrm{V}$, the structural actions and deflections are multiplied by the ratio $\mathrm{V} / \mathrm{V}_{\mathrm{t}}$. In calculating 
the equivalent static base shear the fundamental period of the structure is taken as the smaller of-

(a) the theoretical value found in the modal analysis,

(b) 1.2 times the coefficient, $\mathrm{C}_{u}$, (table 1617.4.2) times the value of $T_{a}$ given by equation 2 in this paper. The value of $\mathrm{C}_{\mathrm{u}}$ varies with the seismicity. For the structures considered in this paper it is 1.2 for the high seismic zone and 1.3 for the low seismic zone.

The minimum design base shear is controlled through the relationship of the design base shear to the equivalent static value. The minimum value, $\mathrm{V}_{\min }$, are given by-

$$
\mathrm{V}_{\min }=0.044 \mathrm{~S}_{\mathrm{DS}}
$$

where $S_{D S}$ is the short period design spectral response acceleration, and it has values of 1.02 and 0.517 for the high and low seismic zones respectively.

For buildings in high seismic zones, where the design spectral one second acceleration equals or exceeds $0.6 \mathrm{~g}$ a further minimum requirement is given by

$$
\mathrm{V}_{\min }=\left(0.5 \mathrm{~S}_{\mathrm{D} 1} \mathrm{I}\right) / \mathrm{R} \text {. }
$$

The IBC code also requires seismic design forces (bending moments, shears and axial forces) to be multiplied by a redundancy coefficient, which increases in magnitude as the redundancy reduces. For the building considered in this paper this factor is unity. In addition in a very limited number of cases all design values have to be increased to allow for P-delta actions (see section 7), though not for the structures considered in this paper.

The deflections obtained from the scaled values of the modal analysis are multiplied by $C_{d} / I$, where $C_{d}$ is the deflection amplifier (given in table 1617.6 in reference 4 ) and $I$ is the importance factor (I has a value of 1.0 for the buildings considered in this paper). This amplification allows for the expected in-elastic deformation associated with ductile behaviour. For the structures considered in this paper $C_{d}$ is 5.5. The value of $C_{d} / R$ is equivalent to the $S_{p}$ factor in the New Zealand Standard. This ratio is 0.69 in the case being considered, but with other structural forms it varies between 0.65 and $1.0^{1}$.

\subsection{Eurocode 8 [5]}

The response spectrum used in the modal analysis is obtained by scaling the elastic response spectrum described in section 3.1. The scale factor changes with the period. For periods in excess of $T_{B}$, which for the soil conditions assumed in this paper is 0.125 seconds, the elastic response spectrum values are divided by the behaviour factor, q. At zero period there is no scaling, while between zero and $T_{B}$ the scale factor varies linearly. The displacements found in the modal analysis are multiplied by the behaviour factor, $\mathrm{q}$, to allow for the expected inelastic deformation in the ultimate limit state. There is a further major difference between the EC 8 and the other codes in the way in which the minimum design base shear is specified. With this code a minimum spectral ordinate of $0.2 \mathrm{ag}$ (peak ground acceleration) is specified The period at which this controls the base shear increases with the behaviour factor, q. For structures where the fundamental mode dominates, such as the ones being considered in this paper, it makes sense to reduce the value of q so that the minimum response spectrum ordinate is just reached. The increased higher mode contributions are minor and the reduced $\mathrm{q}$ value results in a considerable saving in the design displacements, and as such it is an important and logical step, which has been followed in the analyses presented in this paper. Eurocode 8 in some cases requires the strength to be increased to allow for P-delta actions.

\subsection{Structural performance factors $\left(S_{p}\right)$}

As noted above the practice varies in the use of an $S_{p}$ factor in the New Zealand Standard, or its equivalent in the other codes. The current NZ Loadings Standard has an $S_{p}$ factor of 0.67 , unless otherwise specified in the appropriate materials Standards. Essentially the same value is in the Draft NZ/Australian Standard, but with the modification that a value of 1.0 is to be used if the structural ductility factor is less than 1.25. In the UBC code the equivalent of the $S_{p}$ factor is 0.7 . This corresponds to an equivalent structural ductility factor as $5.95(8.5 \times 0.7)$ for the structures considered in this paper. With the IBC code the equivalent of the $S_{p}$ factor is the ratio of the deflection amplification factor, $C_{d}$, divided by response modification factor, $R\left(C_{d} / R\right)$. For the structures considered in this paper this ratio is 0.69 . With other structural forms this ratio varies between 0.65 and 1.0. The value increases as the ductility reduces and as the hysteretic shape of the load displacement response becomes more pinched. This arrangement appears to the writers to have the greatest degree of logic behind it of all the codes.

\subsection{MINIMUM BASE SHEARS}

As described in the previous section each code specifies a different minimum base shears value. These are summarised in Table 1. No such value is specified in the draft $\mathrm{NZ/Australian} \mathrm{Standard} \mathrm{in} \mathrm{the} \mathrm{seismic} \mathrm{provisions.} \mathrm{However,}$ in the general provisions (in part 0 ) each structure is required to be capable of sustaining a lateral force of 0.025 times the dead and long term live loading. This corresponds to a minimum base shear of $0.025 \mathrm{~W}_{\mathrm{t}}$, though the distribution of structural actions up the structure does not correspond to a modal or equivalent static distribution. In the Eurocode 8 code the minimum base shear is found from a response spectrum in which the minimum spectral coefficient is taken as 0.2 times the peak ground acceleration. For this code with regular buildings with 6 or more floors, such as is considered in this paper, the minimum base shear is close to that given in Table 1. An exact value cannot be quoted for Eurocode 8 as it depends on the dynamic properties of the building. For the high seismic zone the New Zealand Standard and the draft NZ/Australian Standard values are very much lower than those in the other codes. However, in the low seismic zone the values found from both the New Zealand Standard and the draft NZ/Australian Standard, are in line with the values in the Uniform Building Code and International Building Code, but lower than the values found using Eurocode 8 .

\footnotetext{
${ }^{1}$ In a later edition of the IBC the range was changed to 0.5 to 1.0
} 
Table 1: Minimum base shear as proportion of seismic weight for regular buildings.

\begin{tabular}{|c|c|c|c|c|c|c|c|c|c|}
\hline \multicolumn{4}{|c|}{ High Seismic Zone } & \multicolumn{5}{c|}{ Low Seismic Zone } \\
\hline NZS & NZ/Aus & UBC & IBC & EC8 & NZS & NZ/Aus & UBC & IBC & EC8 \\
\hline 0.024 & 0.025 & 0.0404 & 0.0449 & $0.079^{*}$ & 0.024 & 0.025 & 0.0208 & 0.0228 & $0.039^{*}$ \\
\hline
\end{tabular}

* Approximate value.

\subsection{SEISMIC INDUCED P-DELTA ACTIONS}

\subsection{General}

Additional bending moments, shears and axial forces are introduced in a building during an earthquake due to P-delta effects. These arise from the gravity loads acting through the lateral displacement of the seismic masses. However, it should be noted, that no additional storey shear is introduced into the building as a whole by this action. A simple way of assessing P-delta effects is illustrated in Figure 3. The gravity loading is applied to laterally flexible framing, which is represented by columns that are pin ended at each floor. The lateral displacement of these columns, due to seismic actions, induces axial forces in the inclined columns and this results in lateral forces being transmitted to the frames. The resultant shear induced in the lateral force resisting elements, which are the frames in these structures, balances the lateral component of the axial forces in the gravity load resisting structure. This approach is general, and as such it gives the correct P-delta actions whether the lateral force resisting elements resist some, none or all, of the gravity load.

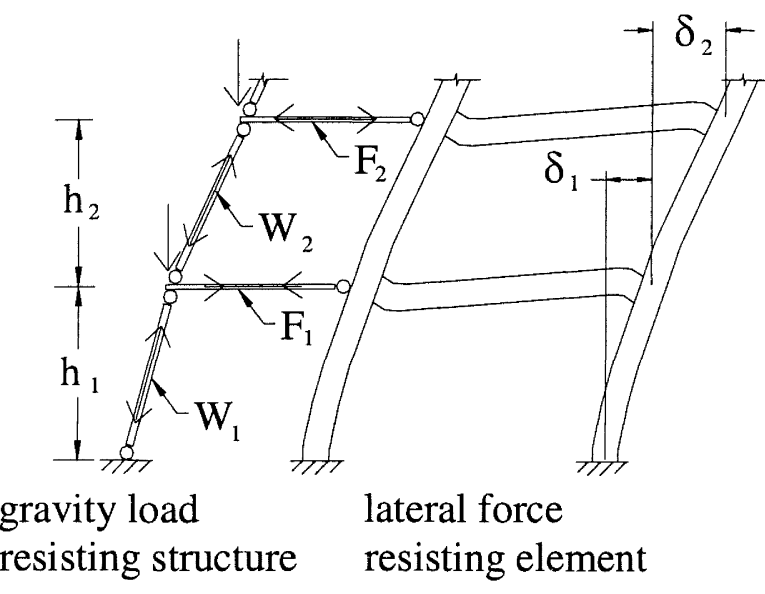

Figure 3: Model for finding P-delta forces in New Zealand Standard.

The potential severity of P-delta actions in frame structures $[11,12]$ can be is assessed from a stability coefficient, $\theta$, which is given by the equation-

$$
\theta_{\mathrm{i}}=\Sigma \mathrm{W}_{\mathrm{i}} \delta_{\mathrm{i}} / \mathrm{V}_{\mathrm{i}} \mathrm{h}_{\mathrm{i}}
$$

where $i$ represents the actions in storey $i, \delta_{i}$ is the interstorey deflection due to the seismic actions but neglecting any increase in deflection resulting from P-delta effects, $h_{i}$ is the inter-storey height, $\Sigma \mathrm{W}_{\mathrm{i}}$ is the gravity load carried by the storey, $i$, and $V_{i}$ is the design shear strength of the storey. Generally the inter-storey displacement, $\delta_{\mathrm{i}}$, corresponds to the value for the ultimate limit state, but without the amplification due to P-delta moments. However, for the
UBC and IBC codes the stability coefficient is based on the displacements sustained at the elastic limit. For simplicity the storey shear strength is generally taken as the design seismic story shear. The stability coefficient, $\theta$, is used in different ways in the five codes.

\subsection{New Zealand Standard}

P-delta actions have to be considered for structures, which exceed $15 \mathrm{~m}$ in height, if the stability coefficient in any storey of the building exceeds 0.133 . The exception to this is where the structure is designed with a ductility factor of 1.5 or less. The stability coefficient is found using the ultimate limitstate displacements, but neglecting the increase in these due to P-delta actions. No method of designing for P-delta actions is specified, but a recommended approach is given in the commentary to the Standard. This approach is outlined below and it has been followed in the analyses described in this paper.

The gravity loads are applied directly to the laterally flexible gravity load resisting structure. From the seismic analysis the displacements at the centre of mass at each level of the structure are found for the ultimate limit state but neglecting any increase in displacements due to P-delta actions. These displacements are applied to the gravity load resisting structure, as illustrated in Fig. 3, and the set of forces, $F_{1}, F_{2}$ etc. required to hold this structure in place are determined. This set of forces reacts against the lateral force resisting elements in the structure. The actions, moments, shears and displacements, which are induced by this set of forces, are multiplied by $\beta \mathrm{K}$. The value of $\beta$ allows for the increasing significance of P-delta actions with increasing ductility, while $\mathrm{K}$ allows for the influence of sub-soil type and fundamental period of the structure on P-delta actions [11]. The values of these two coefficients for intermediate subsoils are given by-

$$
\begin{aligned}
\beta & =2 \mu / 3.5 & & \text { for } \mu<3 . \\
& =2.0 & & \text { for } \mu>3.5 . \\
K & =1.0 & & \text { for } \mathrm{T}<2 \mathrm{~s} \\
& =0.5 & & \text { for } \mathrm{T}>4 \mathrm{~s}
\end{aligned}
$$

The resultant bending moments, shear forces and axial forces found from the application of these forces to the structural model, are added to the corresponding modal values to give the seismic design actions. The deflections are multiplied by the structural ductility factor and added to the modal analysis deflections. The resultant inter-storey displacements are required to comply with the maximum values permitted in the standard (see section 4.3). 


\subsection{Draft NZ/Australian Standard [2]}

The approach followed in this proposed Standard is similar to that of the current New Zealand Loadings Standard, as described above. However, there are a number of differences are set out below.

- P-delta actions do not have to be considered if the fundamental period is less than $0.4 \mathrm{~s}$ or the height of the structure does not exceed given limits for different seismic zones. For the seismic zones considered in this paper the limit is $12 \mathrm{~m}$. (The authors understand that this limit is likely to be changed in the Standard.)

- Allowance has to be made for P-delta actions in the design if the stability coefficient (given by equation 5 ) exceeds 0.1 in any storey of the building.

- In no situation is the stability coefficient allowed to exceed a value of 0.3 .

- One of two specified methods of analysis is to be used for assessing P-delta actions for design. The first of these is a simplified approach, which gives conservative values compared with the second approach. The second method follows the approach recommended in the current New Zealand Standard [1], with one change, as noted below.

- In buildings where there is significant rotation due to torsion the code requires the designer to include this effect into the P-delta analysis. This situation does not arise in the buildings considered in this paper.

\subsection{Uniform Building Code [3]}

This code requires the structural actions in a storey to be amplified by the factor of $1 /\left(1-\theta_{i}\right)$ if the value of the stability coefficient, $\theta_{\mathrm{i}}$, exceeds 0.1 . This coefficient is given by equation 5 . However, in this case the value of $\theta_{\mathrm{i}}$, is based on the elastic inter-storey deflection, $\Delta_{\mathrm{s}}$, rather than the ultimate deflection, which is used in the other codes. As a result the critical value of $\theta_{\mathrm{i}}$ is seldom reached in practice. To enable a direct comparison to be made, the Uniform Building Code limit for the consideration of P-delta actions has been rewritten in Table 2 in terms of the displacement for the ultimate limit state, $\Delta_{\mathrm{m}}$, which is equal to $0.7 \mathrm{R} \Delta_{\mathrm{s}}$. For special moment resisting frames $\mathrm{R}$ is 8.5 .

\subsection{International Building Code [4]}

The approach in this code has many similarities to the UBC code. Structural actions and deflections have to be amplified if a stability coefficient, found for any storey, exceeds 0.1 . As with the UBC this value is found using the elastic interstorey deflection associated with the modal analysis. As for the UBC code this requirement has been rewritten in terms of the ultimate limit state deflections so that a comparison can be made with the other codes. In the IBC code an upper limit to the stability coefficient is given in this document by the expression-

$$
\theta_{\max }=0.5 /\left(\beta C_{d}\right)
$$

where $\beta$ is the ratio of the storey shear strength to the minimum storey design strength, and $C_{d}$ is the deflection amplification factor. The value of $\beta$ may be conservatively taken as 1.0. Greater values indicate a conservative design has occurred. For the structures considered in this project $\beta$ is 1.0 and $C_{d}$ has the value of 5.5. This gives a limiting $\theta_{\max }$ value of close to 0.09 , where $\theta$ is based on the elastic interstorey deflections, or 0.5 if $\theta$ is calculated for the ultimate inter-storey deflection (increased to allow for expected inelastic deformation). As the maximum permitted stability coefficient for ductile frame structures is less than 0.1 the only possible correction for P-delta actions is to increase the stiffness of the frame.

\subsection{Eurocode[8]}

This code requires the inter-storey deflections and structural actions found in the modal analysis to be multiplied by the factor $1 /\left(1-\theta_{i}\right)$ if the stability coefficient equals or exceeds 0.1 but is less than 0.2 . In this case the stability coefficient is based on the inter-storey deflections that have been scaled to allow for the inelastic deformation associated with the ultimate limit-state. With this code there is an upper limit of 0.3 given for the stability coefficient. No indication is given of how the actions should be scaled if the stability coefficient exceeds 0.2 . However, in practice it is difficult to approach this value.

\subsection{Comments on P-delta Code provisions}

Amplification of actions for P-delta effects is seldom required with the UBC and IBC codes as the stability coefficients are based on the elastic deflections, which have not been increased to allow for in-elastic deformation. The logic behind this is difficult to follow, and analytical studies show it is unrealistic [11, 12]. However, limiting the fundamental period that can be used to determine the equivalent static base shear and scaling the modal base shear to a proportion of this value in effect increases the design strength of flexible buildings that might otherwise be sensitive to P-delta actions.

It may be noted that with the UBC, IBC and EC 8 codes the amplification of actions for P-delta effects occurs to a different extent for every storey where the stability coefficient is critical. The amplified values do not satisfy equilibrium. For example a building with a stiff first storey would have a near zero stability coefficient at this level, and hence there would be no increase in design actions required. However, above this level appreciable deflection could well occur, and this would clearly increase the storey bending moment acting on the first storey. This additional storey bending moment is equal to the sum of the lateral displacement at each level times the seismic weight at each level for all the storeys above the level being considered. In that the P-delta amplification fails to allow for this, it is deficient. An advantage of the approach recommended in the New Zealand code is that stability coefficients do not have to be evaluated and applied to each storey and the resultant Pdelta actions do satisfy equilibrium.

Table 2 lists the design P-delta limits from the codes. The lower limit indicates when P-delta effects have to be considered in an analysis and the upper limit indicates when a building has to be re-sized to reduce P-delta actions. To allow a comparison between these limits they have all been written in terms of the ultimate limit state deflections. 
Table 2: Stability coefficient limits for P-delta actions in codes in terms of the ultimate limit state deflections for ductile moment resisting frames.

\begin{tabular}{|c|c|c|c|c|c|}
\hline Item & $\begin{array}{c}\text { NZS 4203 } \\
\mathbf{1 9 9 2}\end{array}$ & $\begin{array}{c}\text { NZ/Australian } \\
\text { draft }\end{array}$ & UBC-1997 & $\begin{array}{c}\text { IBC } \\
\text { (1998 draft) }\end{array}$ & $\begin{array}{c}\text { EC8 } \\
\text { (1998 draft) }\end{array}$ \\
\hline Lower limit & 0.133 & 0.10 & 0.595 & 0.55 & 0.1 \\
\hline $\begin{array}{c}\text { Upper } \\
\text { limit }\end{array}$ & none & 0.30 & none & 0.50 & 0.3 \\
\hline
\end{tabular}

\subsection{DISCUSSION AND RESULTS OF ANALYSES}

The comparative levels of assumed ductility for the buildings, designed to the different codes, are summarised in Table 3. For the New Zealand Standard the values of the structural ductility factor divided by the structural performance factor, $\mu / S_{p}$, are listed. These can be compared directly with the reduction factors, (R), from the UBC and IBC codes, and the behaviour factor, $\mathrm{q}$, from Eurocode 8.

Table 3: Comparison of design ductility factors.

\begin{tabular}{|c|c|c|c|c|c|c|c|c|c|c|}
\hline & \multicolumn{4}{|c|}{ High Seismic Zone } & \multicolumn{4}{c|}{ Low Seismic Zone } \\
\hline $\begin{array}{c}\text { Building } \\
\text { no. of } \\
\text { stories }\end{array}$ & $\mu / \mathrm{S}_{\mathrm{p}}$ & $\mu / \mathrm{S}_{\mathrm{p}}$ & $\mathrm{R}^{*}$ & $\mathrm{R}^{*}$ & $\mathrm{q}$ & $\mu / \mathrm{S}_{\mathrm{p}}$ & $\mu / \mathrm{S}_{\mathrm{p}}$ & $\mathrm{R} *$ & $\mathrm{R}^{*}$ & $\mathrm{Q}$ \\
\hline 6 & 9 & 9 & 8.5 & 8 & 5 & 7.6 & 9 & 8.5 & 8 & 5 \\
\hline 12 & 9 & 9 & 8.5 & 8 & 5 & 4.7 & 8.5 & 8.5 & 8 & 5 \\
\hline 18 & 6.7 & 9 & 8.5 & 8 & 5 & 3.1 & 6.2 & 8.5 & 8 & 4.6 \\
\hline 24 & 4.4 & 9 & 8.5 & 8 & 4.6 & 2.2 & 4.9 & 8.5 & 8 & 3.6 \\
\hline
\end{tabular}

*Note- no method of varying the ductility factor for a given building is provided in the UBC or IBC codes

With both the New Zealand Standard and the draft NZ/Australian Standard the maximum permitted value of structural ductility factor divided by structural performance factor is 9 . For the 18 and 24 storey frames in the high seismic zone and all the frames in the low seismic zone the level of required ductility was limited to a lower value as the minimum base shear controlled the design strengths. A similar situation occurred with the 18 and 24 storey frames analysed to Eurocode 8 . In this case the base shears were limited by the minimum spectral ordinate, which results in a reduced value of behaviour factor, $\mathrm{q}$.

In Table 4, which is for the high seismic zone, a relative size factor is given for all the frames, while in Table 5, which is for the low seismic zone, the size factor was kept at 1.0, except for the 24 storey building where the section sizes had to be increased with the Eurocode 8 analyses to meet the stiffness requirements of that code. For the high seismic zone this factor gives a measure of the relative change of linear dimensions of the basic frame members that is required so that the inter-story deflections just comply with the code inter-storey deflection limit. It is assumed to be proportional to the $4^{\text {th }}$ root of the required change in stiffness

The variation in the analytical fundamental period found with the different codes has two principle causes. The first is the change in member dimensions, and the second is the differences in the way the section properties are evaluated in the different codes. The relative magnitudes of both components can be readily assessed. The first of these is proportional to the inverse of the square of the relative size factor. From this table it can be seen that the fundamental periods calculated with the Eurocode 8 were approximately $60 \%$ of the corresponding values found following the New Zealand codes, with the UBC and IBC values lying between these.
As noted previously with UBC and IBC codes a nominal period has to be determined and where this is less that the theoretical fundamental period it is used to assess the minimum base shear. It can be seen that the nominal periods were critical in all the frames analyses considered in this paper, which were analyses following the recommendations of these two codes. It is this factor, which leads to a significant increase in the design strengths when compared to the corresponding values found using the New Zealand and draft NZ/Australian Standards. Given the sensitivity of the required strengths to the fundamental period, and the difficulty of obtaining a realistic value of this period [13], the provision in the UBC and IBC codes seems to be appropriate.

Figure 4(a) compares the relative base shears for the frames the region of high seismicity. It can be seen that there is relatively little difference between the base shears required with the New Zealand Standard and the draft NZ/Australian Standard. However, the difference between these values and those required by the other codes is large. Eurocode 8 requires up to 4.0 times and the Uniform Building Code and International Building code up 1.9 times, the base shear required by the New Zealand Standard. The required strength differences are reduced, when the additional strength required for P-delta actions is included, as illustrated in Figure 5. In the low seismic zone the differences are less extreme. In this case the Eurocode 8 values stand out as high from the rest. The significance of P-delta actions with the New Zealand code should be noted. In the high seismic zone these actions typically increase the design strengths in the critical storeys by 50 to 60 percent. A major problem here is that the method of allowing for P-delta actions in this code is recommended and not specified. In the draft NZ/Australian Standard, however, a method of including P-delta effects is specified. 
Table 4: High Seismic Zones

\begin{tabular}{|l|c|c|c|c|c|}
\hline 6 storey & NZS 4203 & NZ/Aust & UBC-1997 & IBC-2000 & EC8 \\
\hline Relative size factor & 1.02 & 1.04 & 0.81 & 0.80 & 1.02 \\
\hline $\mathrm{T}_{1}$ analytical & 1.38 & 1.35 & 1.97 & 2.00 & 0.80 \\
\hline $\mathrm{T}_{1}$ nominal & - & & 0.91 & 1.01 & - \\
\hline Base shear proportion $\mathrm{W}_{\mathrm{t}}$ & 0.0425 & 0.0453 & 0.0766 & 0.0449 & 0.1502 \\
\hline P-delta amplification. & 1.52 & 1.49 & 1.0 & 1.0 & 1.0 \\
\hline Relative stiffness to NZS & 1.0. & 1.06 & 0.39 & 0.38 & 1.01 \\
\hline
\end{tabular}

\begin{tabular}{|l|c|c|c|c|c|}
\hline 12 storey & NZS 4203 & NZ/Aust & UBC-1997 & IBC-2000 & EC8 \\
\hline Relative size factor & 1.01 & 1.02 & 0.85 & 0.85 & 1.01 \\
\hline $\mathrm{T}_{1}$ analytical & 2.72 & 2.22 & 2.85 & 2.88 & 1.35 \\
\hline $\mathrm{T}_{1}$ nominal & - & & 1.53 & 1.70 & - \\
\hline Base shear proportion $\mathrm{W}_{\mathrm{t}}$ & 0.0255 & 0.0274 & 0.0456 & 0.0499 & 0.1018 \\
\hline P-delta amplification. & 1.62 & 1.60 & 1.0 & 1.0 & 1.11 \\
\hline Relative stiffness to NZS & 1.0 & 1.05 & 0.51 & 0.50 & 1.00 \\
\hline
\end{tabular}

\begin{tabular}{|l|c|c|c|c|c|}
\hline 18 storey & NZS 4203 & NZ/Aust & UBC-1997 & IBC-2000 & EC8 \\
\hline Relative size factor & 1.04 & 1.20 & 0.98 & 0.98 & 1.13 \\
\hline $\mathrm{T}_{1}$ analytical & 3.35 & 2.55 & 3.43 & 3.44 & 1.76 \\
\hline $\mathrm{T}_{1}$ nominal & - & & 2.08 & 2.30 & - \\
\hline Base shear proportion $\mathrm{W}_{\mathrm{t}}$ & 0.024 & 0.031 & 0.0436 & 0.0449 & 0.0856 \\
\hline P-delta amplification. & 1.52 & 1.52 & 1.00 & 1.0 & 1.12 \\
\hline Relative stiffness to NZS & 1.00 & 1.76 & 0.78 & 0.77 & 1.36 \\
\hline
\end{tabular}

\begin{tabular}{|l|c|c|c|c|c|}
\hline 24 storey & NZS 4203 & NZ/Aust & UBC-1997 & IBC-2000 & EC8 \\
\hline Relative size factor & 1.01 & 1.11 & 1.97 & 1.08 & 1.21 \\
\hline $\mathrm{T}_{1}$ analytical & 5.08 & 4.16 & 5.01 & 4.01 & 2.21 \\
\hline $\mathrm{T}_{1}$ nominal & - & & 2.58 & 2.86 & - \\
\hline Base shear proportion $\mathrm{W}_{\mathrm{t}}$ & 0.024 & $\begin{array}{c}0.025 \\
(0.0156)\end{array}$ & 0.0436 & 0.0449 & 0.0790 \\
\hline P-delta amplification. & 1.36 & $\begin{array}{c}1.03 \\
(1.57)\end{array}$ & 1.00 & 1.0 & 1.13 \\
\hline Relative stiffness to NZS & 1.00 & 1.52 & 0.86 & 1.34 & 2.12 \\
\hline
\end{tabular}


Table 5: Low Seismic Zone Results

\begin{tabular}{|l|c|c|c|c|c|}
\hline 6 storey & NZS & NZ/Aust & UBC & IBC & EC8 \\
\hline $\mathrm{T}_{1}$ analytical & 1.44 & 1.44 & 1.28 & 1.28 & 0.83 \\
\hline $\mathrm{T}_{1}$ nominal & & & 0.98 & 1.10 & \\
\hline Base shear (proportion of $\mathrm{W}_{\mathrm{t}}$ ) & 0.024 & $\begin{array}{c}0.025 \\
(0.021)\end{array}$ & 0.0356 & 0.0264 & 0.0735 \\
\hline P-delta amplification & 1.47 & $\begin{array}{c}1.48 \\
(1.56)\end{array}$ & 1.00 & 1.00 & 1.00 \\
\hline $\begin{array}{l}\text { Proportion of maximum } \\
\text { allow inter-storey deflection }\end{array}$ & 0.50 & 0.56 & 0.34 & 0.30 & 0.54 \\
\hline
\end{tabular}

\begin{tabular}{|l|c|c|c|c|c|}
\hline 12 storey & NZS & NZ/Aust & UBC & IBC & EC8 \\
\hline $\mathrm{T}_{1}$ analytical & 2.32 & 2.32 & 2.08 & 2.08 & 1.38 \\
\hline $\mathrm{T}_{1}$ nominal & & & 1.65 & 1.84 & \\
\hline Base shear (proportion of $\mathrm{W}_{\mathrm{t}}$ ) & 0.024 & $\begin{array}{c}0.025 \\
(0.0131)\end{array}$ & 0.0225 & 0.0227 & 0.0511 \\
\hline P-delta amplification & 1.30 & $\begin{array}{c}1.00 \\
(1.65)\end{array}$ & 1.00 & 1.00 & 1.11 \\
\hline $\begin{array}{l}\text { Proportion of maximum } \\
\text { allow inter-storey deflection }\end{array}$ & 0.41 & 0.54 & 0.26 & 0.32 & 0.54 \\
\hline
\end{tabular}

\begin{tabular}{|l|c|c|c|c|c|}
\hline 18 storey & NZS & NZ/Aust & UBC & IBC & EC8 \\
\hline $\mathrm{T}_{1}$ analytical & 3.65 & 3.65 & 3.30 & 3.30 & 2.24 \\
\hline $\mathrm{T}_{1}$ nominal & & & 2.24 & 2.50 & \\
\hline Base shear (proportion of $\mathrm{W}_{\mathrm{t}}$ ) & 0.024 & $\begin{array}{c}0.025 \\
(0.0095)\end{array}$ & 0.0225 & 0.0227 & 0.0397 \\
\hline P-delta amplification & 1.15 & $\begin{array}{c}1.00 \\
(1.72)\end{array}$ & 1.00 & 1.00 & 1.20 \\
\hline $\begin{array}{l}\text { Proportion of maximum } \\
\text { allow inter-storey deflection }\end{array}$ & 0.41 & 0.70 & 0.28 & 0.56 & 0.74 \\
\hline
\end{tabular}

\begin{tabular}{|l|c|c|c|c|c|}
\hline 24 storey & NZS & NZ/Aust & UBC & IBC & EC8 \\
\hline Relative size factor & 1.0 & 1.0 & 1.0 & 1.09 & 1.0 \\
\hline $\mathrm{T}_{1}$ analytical & 5.13 & 5.13 & 4.70 & 3.97 & 3.26 \\
\hline $\mathrm{T}_{1}$ nominal & & & 2.78 & 3.10 & \\
\hline Base shear (proportion of $\left.\mathrm{W}_{\mathrm{t}}\right)$ & 0.024 & $\begin{array}{c}0.025 \\
(0.0088)\end{array}$ & 0.0225 & 0.0227 & 0.0397 \\
\hline P-delta amplification & 1.00 & $\begin{array}{c}1.0 \\
(1.89)\end{array}$ & 1.00 & 1.00 & 1.25 \\
\hline $\begin{array}{l}\text { Proportion of maximum } \\
\text { allow inter-storey deflection }\end{array}$ & 0.37 & 0.76 & 0.29 & $0.59 *$ & 0.92 \\
\hline
\end{tabular}

* stiffened by stiffness change factor of 1.4 in order to meet minimum requirement of stability coefficient $\theta \leq 0.091$. 
In terms of stiffness criteria it can be seen from Tables 4 and 5 that the New Zealand codes and Eurocode values are comparable in the high seismic zone for the 6,12 and 18 storey frames. However, Eurocode 8 requires in excess of a 100 percent increase in stiffness for the 24 storey structure compare with the requirements from the New Zealand codes. For all but the 24 storey frame the UBC and IBC codes accept appreciable lower stiffness values than the corresponding New Zealand codes. The exception is the 24 storey frame with the IBC code where a $34 \%$ relative increase in stiffness is required.
With the draft NZ/Australian Standard an increase in return (importance) factor from 1.0 to 1.3 that occurs when the number of storeys exceeds 16 . This does not result in an appreciable increase in required strength compared with that required with the New Zealand loadings Standard, as the 1.3 factor applies only to the seismic strength requirements and not to the nominal strength requirement of $0.025 \mathrm{~W}_{\mathrm{t}}$ from the robustness requirements in Part 0 . For the 18 and 24 storey frames it is this requirement that is critical.

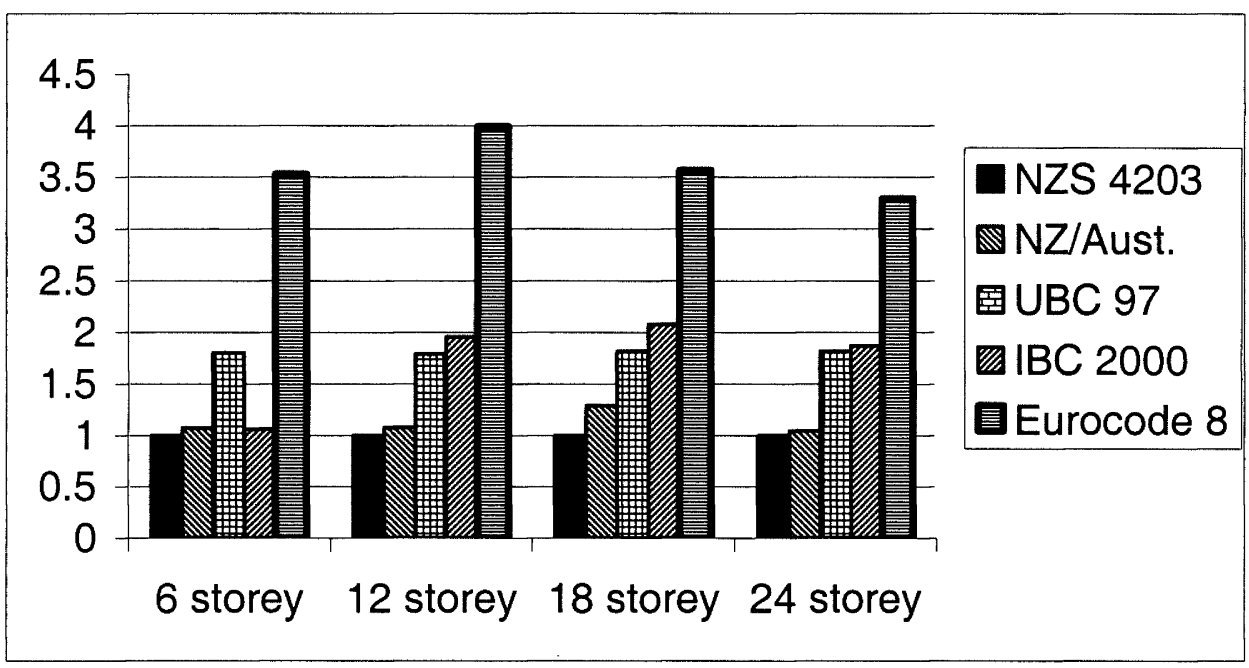

(a) Base shear high seismic zone

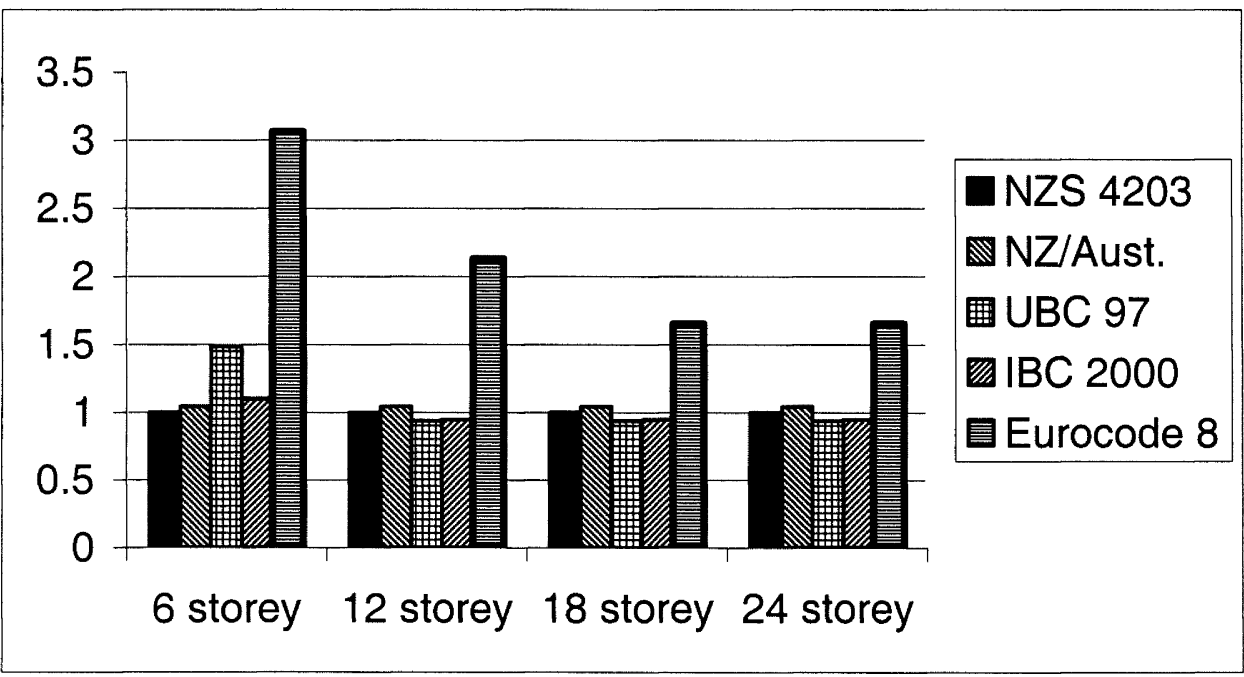

(b) base shear low seismic zone

Figure 4: Comparison of base shears for different codes. 


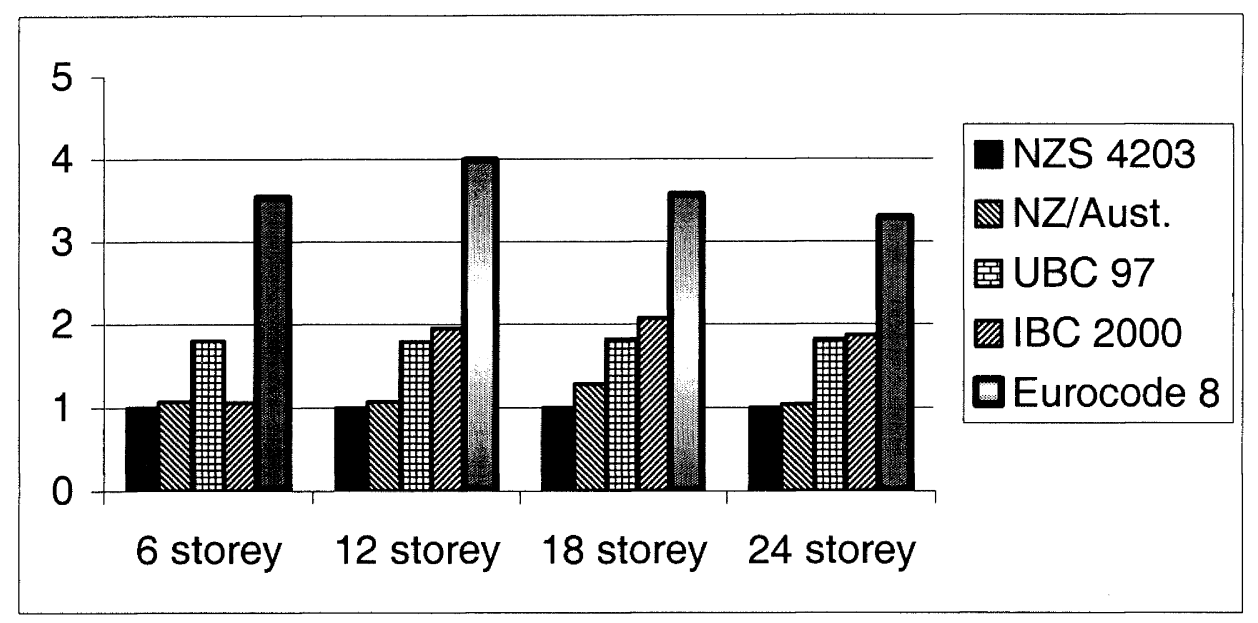

(a) High seismic zone

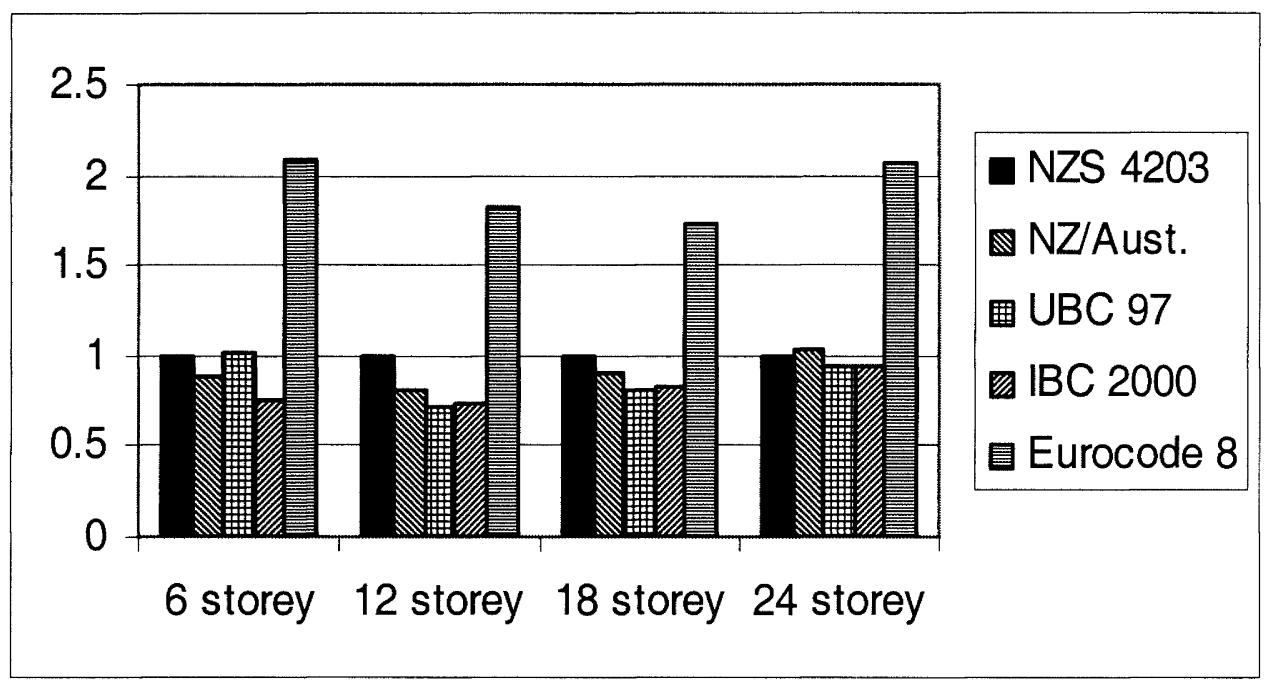

(b) Low seismic zone

Figure 5: Relative frame shears with P-delta effects

Ductile high rise moment resisting frame buildings tend to be sensitive to seismic induced P-delta actions. A practical way of reducing this sensitivity would be to adopt a similar approach to that used in Eurocode 8. That is to use a response spectrum for analysis, which has a minimum value of a constant times the peak ground acceleration. With Eurocode 8 this constant is 0.2 . As this gives a rather high minimum base shear it is suggested that a minimum value of $0.15 \mathrm{~S}_{\mathrm{p}}$ times the peak ground acceleration might be appropriate. Such a value would result a minimum base shear of the order of $0.038 \mathrm{~W}_{\mathrm{t}}$ for these two buildings, which would be inline with the values found from the UBC and IBC codes.

The strengths required for seismic induced actions in both the New Zealand Loadings and the draft NZ/Australian Standard, together with the appropriate materials standards, are much less than the corresponding values required in well accepted international codes such as the UBC and IBC. Either the strengths required by the draft Standard should be increased, or a major study should be undertaken to show that these lower strengths provide adequate performance from the point of view of life safety. In addition it would be of value to both designers and building owners if the relationship between strength and economic performance of buildings could be established with respect to the costs involved in repair of seismic induced damage. It should be noted that at present in New Zealand, generally only a low proportion of reinforcement is used in reinforced concrete buildings. For this group increasing the reinforcement proportion by 0.01 would give a cost increase of the order of 1 percent and a strength increase of the order of 50 percent.

It should be noted that the comparative analyses reported in this paper are restricted to a series of multi-storey ductile moment resisting frames. In comparing the draft code to international recognised codes of practice it would be desirable to have comparative analyses for a much wider range of structural types and building sizes. 


\subsection{CONCLUSIONS}

1. Due to the interaction between the clauses in codes of practice only very limited conclusions can be drawn by comparing individual aspects, such as P-delta effects, or inter-storey drift limits in the different codes. However, realistic conclusions can be drawn by comparing the results of analyses made for the same structure designed using each individual code.

2. The basic hazard response elastic response spectra for all the codes were very similar to each other in both shape and the magnitude of the spectral values. However, the way in which the required strengths are determined form these spectra lead to very different values. Some of this difference can be put down to different assumptions contained in the codes, or for the case of the NZ based Standards the material standard for Structural Concrete [8], relating to the way in which the stiffness of members is assessed. Significant differences arise from the minimum base shear coefficients contained in the codes and from the way in which the critical fundamental period of a structure is assessed.

3. The required strength levels for the high seismic zone found using the New Zealand Loadings Standard and the draft NZ/Australian Standard were appreciable less than those found using the UBC and IBC codes of practice and very much less than the corresponding values in Eurocode 8.

4. Either the design strengths for the ductile moment resisting frame buildings required by the draft Loadings Standard should be increased to be comparable to those required by well recognised international standards, such as the UBC and IBC codes, or a major study should be undertaken to demonstrate that these low strengths provide adequate life safety and economic performance.

5. It is noted that an appreciable strength increase can generally be obtained for a small increase in total cost.

6 For the low seismic zone the strength requirements of the New Zealand Loadings Standard and the draft NZ/Australian Standard are comparable to those in the IBC and UBC codes.

7. It would be desirable to have a much wider study, which included a range of structural forms, to enable the draft NZ/Australian Loadings Standard to be compared with internationally accepted codes of practice.

\section{REFERENCES}

1 NZS, 1992, "General Structural Design and Design Loadings for Buildings, NZS 4203 -1992”, Standards New Zealand.

2 NZS AS, "Draft Revision of AS 1170.4 and NZS 4203:1992", Feb. 2001 but including Part 4, revision of 20-02-2002.

3 ICBO, 1997, "Uniform Building Code 97", Vol. 2. International Conference of Building Officials, Whittier, $C A$.

4 BOCA and ICBO, 1998, "International Building Code, sections 16 and 19”, final draft, July 1998.

5 Eurocode 8, 1998, “Design Provisions for earthquake resistant structures" Parts 1.1, $1.2 \&$ \& 1.3. Draft for Development. BSI.

6 Booth, E. D., Kappos, A. J. and Park, R., "A critical review of international practice on seismic design of reinforced concrete buildings", The Structural Engineer, Vol. 76, No. 11, June 1998, pp213-220.

7 Fenwick, R. C., Davidson, B. J. and Booth, E., "A comparison of seismic design actions in Eurocode 8, Uniform Building Code and the New Zealand Loadings Standard", Australasian Structural Conference, Auckland Oct. 1998, Vol. 1, pp411-417.

8 NZS 3101-1995, "Concrete Structures Standard, Design of Concrete Structures", Standards Association New Zealand, Pat 1, 256p, Part 2, 264p.

9 SAP2000, Computers and Structures Inc. Berkeley, California. 1998.

10 European Committee for Standardisation, "design of concrete structures, Part 1, General rules and rules for buildings", Eurocode 2, 1992, pp253.

11 Fenwick, R. C., Davidson, B. J. and Chung, B. T., "Pdelta actions in seismic resistant Structures" Bulletin New Zealand National Society for Earthquake Engineering, Vol.25, No. 1, March.1992, pp56-69.

12 Bernal, D., "Amplification factors for inelastic dynamic P-delta effects in earthquake analysis", Earthquake Engineering and Structural Dynamics, Vol. 15, 1987, pp635-651.

13 Ellis, B. R., "An assessment of the accuracy of predicting the fundamental natural frequency of buildings and the implications concerning dynamic analysis of structures", Proceedings of the ICE (London), Sept. 1980, Vol. 69, Pt. 2, pp 763-776. 